\title{
The renin-angiotensin system and cardiac remodelling after acute myocardial infarction
}

\author{
H Ikram
}

\begin{abstract}
Elsewhere in this supplement, evidence is presented concerning several properties of the renin-angiotensin system which influence the entire gamut of ischaemic heart disease, from atheroma to terminal heart failure. Acute myocardial infarction and the resulting changes occupy a central position in this evolutionary process. Cardiac changes in response to acute infarction are termed "ventricular remodelling", which is defined as changes in left ventricular geometry with hypertrophy and dilatation not due to short term changes in loading conditions. These are initially adaptive but eventually progress and become maladaptive, resulting in progression to chronic heart failure. The contention is that these structural and geometric changes in the left ventricle are the basis for the ultimate development of heart failure and death, irrespective of the aetiology of the myocardial damage. The "ventricular remodelling" hypothesis attempts to offer a unifying concept for the generic behaviour of the cardiovascular system in response to increased load. The purpose of this paper is to review the nature and management of ventricular remodelling as it pertains to the reninangiotensin system.
\end{abstract}

\section{Changes in the heart following acute myocardial infarction}

The occurrence of an acute myocardial infarct represents a catastrophic upheaval in pathophysiological terms. There are major changes in the infarcted area as well as in the normal myocardium. In addition, there is activation of a large series of neuroendocrine systems, notably the renin-angiotensin-aldosterone system. Superadded to these are the effects of acute treatment, especially thrombolysis and $\beta$ blockade.

The intensity of these changes varies with the time after onset, size and location of the

\section{Glossary of trials}

AIRE-Acute Infarction Ramipril Efficacy Study

CONSENSUS II-Cooperative New Scandinavian Enalapril Survival Study

GISSI-3-Gruppo Italiano per lo Studio della Sopravvivenza nell'infarto Miocardico

ISIS-4-Fourth International Study of Infarct Survival

PRACTICAL-Placebo-Controlled Randomised ACE Inhibitor Comparative Trial in Cardiac Infarction and LV Function

SAVE-Survival And Ventricular Enlargement Study

SOLVD-Studies Of Left Ventricular Dysfunction infarct, and the patency of the infarct related artery. In the earliest phase after infarction, there is infarct thinning, which occurs from 0 to 6 hours after the onset of infarction, and infarct extension which lasts from days to weeks after the onset of chest pain. ${ }^{12}$ Infarct expansion is limited for the first few weeks after acute infarction. Beginning days later and lasting for months are more insidious changes of compensatory left ventricular dilatation and hypertrophy. These affect the assumption of a more spherical shape by the ventricle as a whole. Neuroendocrine compensatory changes are more chronic, occurring weeks to years later. This constellation of structural and geometric changes in the left ventricle are termed "ventricular remodelling". ${ }^{1}$

These changes are initially adaptive, helping to preserve cardiac performance and permitting enhanced development of left ventricular pressure and stroke volume. They may not progress any further, especially if the infarcted area is small, located inferiorly, and the infarct related artery is patent. ${ }^{3}$ In the absence of these favourable factors, the "remodelling" process continues to progress to further dilatation and hypertrophy, declining systolic function, and eventually the development of clinically overt heart failure.

The renin-angiotensin system and postmyocardial infarction remodelling

Based on experimental observations on the coronary ligation model of the rat heart, Pfeffer $e t a l^{45}$ hypothesised that these changes in the myocardium were a result of altered loading conditions, with increased wall stress in the infarcted and surviving areas of the myocardium.

Angiotensin converting enzyme (ACE) inhibitors reduce wall stress and have been used successfully in the treatment of heart failure. They were tested in the setting of experimental infarction and were found to reduce the changes of ventricular remodelling. ACE inhibitors improved survival in animals with moderate sized infarcts; however, survival was not improved when the animals sustained small or large infarctions. ${ }^{67}$

With this pathophysiological framework, initial clinical studies were undertaken. These studies confirmed the beneficial effects of captopril given 24 hours or more after the onset of acute infarction on left ventricular remodelling changes in anterior infarction, ${ }^{8}$ and anterior and inferior infarction. ${ }^{9}$

The intent of the early studies on ACE inhi- 
bition in acute myocardial infarction was to establish that ACE inhibitors favourably influenced the changes of ventricular remodelling, even in the absence of any clinical evidence of heart failure or left ventricular dysfunction. Another important consideration was to establish the safety of these hypotensive agents in the already hypotension-prone setting of acute infarction.

\section{Clinical outcome trials}

The trials previously quoted, and several others, clearly established the efficacy of ACE inhibitors in attenuating the maladaptive remodelling changes seen particularly after large $Q$ wave anterior infarctions. However, the ultimate test to prove that the use of ACE inhibitors was beneficial to patients suffering from myocardial infarction was to show improved mortality and morbidity in an appropriately powered clinical trial. With this objective, the SAVE (survival and ventricular enlargement) trial was undertaken. ${ }^{10}$ This was the first study to test the ACE inhibitor/ remodelling hypothesis in acute myocardial infarction. The study showed that the ACE inhibitor captopril was very effective in reducing total mortality, cardiovascular mortality, and the development of heart failure when given in a dose of $150 \mathrm{mg}$ daily to asymptomatic patients with ejection fractions of less than $40 \%, 5-16$ (mean 11) days after acute infarction. The risk reduction was $19 \%$ for mortality $(P<0.019)$. The interesting feature of this trial was that the beneficial effects were only noted after 12 months of treatment.

A comparable study was the AIRE (acute infarction ramipril evaluation) study, ${ }^{11}$ although the population studied was more ill than that in the SAVE study. Clinical evidence of heart failure was the criterion for entry into the SAVE study; ejection fraction was not a requirement. Ramipril was given within 3 to 10 (mean 5) days following infarction and the progress of the patients was followed for a year. These data show that there was a significant reduction in cardiovascular mortality (risk reduction 27\%; P $<0.002$ ). The AIRE study differed from the SAVE study in that the beneficial effects were manifested immediately.

Another important pair of studies were the SOLVD (survival of left ventricular dilatation) trials. The criterion for entry into these studies was an ejection fraction of less than $35 \%$. Sixty six per cent of the patients enrolled in the SOLVD studies had ischaemic heart disease, including acute infarction in the past. Hence these were not strictly post-acute myocardial infarction trials in the sense that AIRE and SAVE were, but nevertheless provided a different perspective in that they addressed the patient's outcome when ACE inhibition was introduced late in the course of the postinfarction period. The SOLVD trials had two arms, the treatment $\operatorname{arm}^{12}$ which recruited patients with a history of clinical heart failure, and the prevention $\operatorname{arm}^{13}$ which recruited patients who had never had clinical heart failure but who did have ejection fractions of less than $35 \%$.

The treatment study confirmed that administration of enalapril to a group of patients who had experienced heart failure at a late stage after acute infarction does result in improved survival and reduced hospital stay with heart failure. The prevention trial showed that ACE inhibition can reduce the occurrence of heart failure in asymptomatic patients, although mortality was not reduced.

From these data and other smaller studies, it is now well established that in the days following acute myocardial infarction the administration of ACE inhibitors to patients with impaired systolic function reduces subsequent mortality and morbidity from cardiac causes. The next obvious question was whether even earlier administration to unselected patients with heart attacks would be more effective, if it was tolerated.

The earliest attempt to examine this question was in the CONSENSUS II trial. ${ }^{14}$ This trial required the intravenous administration of enalaprilat to patients with acute infarction immediately on their admission to hospital. The trial was terminated prematurely on grounds of lack of efficacy (risk reduction $-7 \%$ to $+29 \%$ ), but there were also concerns regarding the safety of the drug treatment. There are some experimental data suggesting that very early administration of ACE inhibitors after acute infarction could be deleterious as it may impair healing. ${ }^{15}$

Despite these unpropitious beginnings, studies examining the effects of very early administration of ACE inhibitors in acute infarction continued to be performed. Some of these studies are among the largest trials ever done in medicine. The ISIS-4 trial $^{16}$ was a factorial trial examining the effects of captopril, nitrates, and magnesium in unselected patients treated within 24 hours of the onset of acute infarction. The study population comprised 58824 patients. The end point was 35 -day mortality. There was a $6 \%$ risk reduction which was significant at $\mathrm{P}<0.04$. The GISSI- $3^{17}$ enrolled 18985 patients. Lisinopril was administered on admission and the primary end point was 6-week mortality. Treatment resulted in an $11 \%$ risk reduction which was statistically significant at the $0.03 \%$ level. An interim report on 13000 patients from the Chinese captopril study has been published. ${ }^{18}$

From these data it is clear that administration of ACE inhibitors within hours of the onset of an acute infarct is safe and reduces mortality by a small but statistically significant amount. The magnitude is about five lives saved per 1000 patients treated. However, the use of ACE inhibitors in this situation is in addition to all available conventional treatment including thrombolysis and $\beta$ blockade. An approximation of the relative benefits of various treatment regimes in acute infarction and related cardiovascular conditions is given in the table. ${ }^{19}$ There may be additional benefits with longer term follow up or with continued treatment. 
Treatment benefits in cardiovascular disease

\begin{tabular}{llc}
\hline Treatment & Events prevented & $\begin{array}{c}\text { Patients treated } \\
\text { for five years }\end{array}$ \\
\hline Hypertension (DBP 115-129) & Death, CVA, MI & 3 \\
CABG for LMS stenosis & Death & 3 \\
$\begin{array}{l}\text { Warfarin for AF } \\
\text { (secondary prevention) }\end{array}$ & CVA & 3 \\
$\begin{array}{c}\text { ACE inhibitor-heart failure } \\
\text { post-MI }\end{array}$ & Death, MI, CVA, CHF & 4 \\
$\begin{array}{l}\text { ASA for TIA } \\
\text { Warfarin for AF }\end{array}$ & Death, CVA & 6 \\
$\quad$ primary prevention) & CVA & 7 \\
$\begin{array}{l}\text { ACE inhibitor for mild CHF } \\
\text { ACE inhibitor for LV }\end{array} \quad$ & CV death, hosp (CHF) \\
$\quad$ dysfunction post-MI & CV death, hosp (CHF) & 8 \\
$\begin{array}{l}\text { HMG-CoA reductase } \\
\text { inhibitor post-MI }\end{array}$ & CV death, MI, & 10 \\
$\begin{array}{l}\text { Aspirin post-MI } \\
\text { Hypertension (DBP 90-109) }\end{array}$ & cardiac arrest & 11 \\
\hline
\end{tabular}

${ }^{\star}$ Based on SAVE study.

$\star \star$ Based on AIRE study.

CV, cardiovascular; LV, left ventricular; MI, myocardial infarction; TIA, transient ischaemic

CV, cardiovascular; LV, left ventricular; MI, myocardial infarction; TIA, transient ischaemic
attack; ASA, aspirin; CVA, cerebrovascular accident; DBP, diastolic blood pressure; CABG, attack; ASA, aspirin; CVA, cerebrovascular accident; DBP, diastolic blood pressure; CABG,
coronary artery bypass grafting; AF, atrial fibrillation; LMS, left main stem coronary artery; coronary artery bypass grafting; $\mathrm{AF}$, atrial fibrillation; $\mathrm{LM}$
hosp (CHF), hospital admission for chronic heart failure.

hosp (CHF), hospital admission for chronic heart failure.
[benefits of common cardiovascular treatments based on the number needed to treat, (NNT) concept, ie, how many patients need to be treated for five years to prevent one major event].

\section{Outstanding questions concerning ACE inhibition for myocardial infarction} BENEFITS DUE TO CLASS EFFECT OR DRUG SPECIFIC EFFECTS?

In the early days of research into the actions of ACE inhibitors in acute myocardial infarction there was a series of studies which suggested that agents such as captopril which had an $\mathrm{SH}$ group in the molecule, might have a uniquely cardioprotective role in ischaemia. Captopril potentiates the coronary vasodilator response to dinitrate in experimental models whereas ramiprilat, which does not have an $\mathrm{SH}$ group, does not. ${ }^{20}$

Another question related to the "drug" versus "class" issue was whether drugs with a rapid onset and shorter duration of action were more effective than agents which were given as pro-drugs and required hepatic conversion to the active state. This hypothesis was tested directly in the PRACTICAL study with a head to head comparison of enalapril and captopril. ${ }^{21}$ Both ACE inhibitors had equally beneficial effects on ventricular remodelling and function, suggesting that the benefits on ventricular function were a class effect common to all ACE inhibitors.

Further evidence that this is also true for mortality effects comes from the mega-trials. Short acting agents with an $\mathrm{SH}$ group (captopril), long acting agents with an $\mathrm{SH}$ group (zofenopril), and long acting agents without $\mathrm{SH}$ groups (enalapril, trandolapril, and ramipril) all have beneficial effects on mortality and morbidity following acute infarction. ${ }^{10-1216-1821-23}$ This issue appears to have been settled.

OPTIMAL TIMING OF ADMINISTRATIONIMMEDIATE, EARLY, OR LATE AFTER ONSET OF INFARCTION

There has been some controversy over the risks versus benefits of giving ACE inhibitors at various times after the onset of infarction. Administration regimens are defined as "immediate" if given within a few hours (less than 24) after onset, "early" if given within a few days after onset, and "late" if delayed for weeks or months. The problem with regard to the optimal time for initiating ACE inhibition following acute infarction persists, because all the immediate administration trials have been in unselected populations, whereas the later administration trials have been in patients selected because of reduced left ventricular function or clinical heart failure. Patients with reduced left ventricular function or clinical heart failure are at a significantly greater risk of dying, and hence will be expected to show a greater magnitude of improvement. Thus the relative risk of acute myocardial infarction in patients with bilateral rales is $3 \cdot 3$, with an ejection fraction less than $40 \%$ is $2 \cdot 4$, and with both of these is $7 \cdot 9 .^{24}$

Delayed administration of ACE inhibitors, as in SAVE and AIRE, to selected patients appears to provide a greater absolute benefit, as would be expected in a population at substantially higher risk. But two facts seem to have been unequivocally established: first, that immediate administration of ACE inhibitors a few hours after the onset of infarction is safe; and second, that there is a clear, if small, improvement in mortality which may be additional to conventional treatment. In the final analysis, whether the saving of five to six lives per 1000 patients treated is worthwhile or not is a philosophical, not a medical, question. The answer would be unequivocally in the affirmative if prevention of recurrent infarction by these drugs after infarction, in a recent follow up of the SAVE patients, ${ }^{25}$ had been shown to be independent of ventricular function.

\section{OPTIMAL DOSE OF ACE INHIBITORS IN} MYOCARDIAL INFARCTION

The question of optimal dose continues to bedevil the treatment of patients with acute myocardial infarction. Clinical trialists seek to use the highest tolerated dose in order not to end up with a trial which shows no effect, whereas usual clinical practice requires the lowest effective dose in order to avoid side effects and encourage compliance. Recent interest in economic cost-benefit ratios of all therapeutic drugs would also tend to seek the minimum dose. Acute infarction is a highly unstable state and the intrinsic hypotensive propensity is exacerbated by thrombolysis, $\beta$ blockade, and opiate administration, so the tolerance range of ACE inhibitors is rather low. In this context, it should be remembered that only approximately $15 \%$ of the potentially randomisable population actually enters the randomised trial, making it difficult to generalise the results to post-infarction patients as a whole.

In the absence of proper dose ranging studies, one has to seek guidance from the clinical trial data. As regards to immediate intervention studies with mortality end points, GISSI-3 used lisinopril $10 \mathrm{mg}$ once daily, ISIS- 4 used $50 \mathrm{mg}$ twice daily, and the Chinese captopril study gave captopril as $12.5 \mathrm{mg}$ thrice daily. In the PRACTICAL study the dose of captopril was $25 \mathrm{mg}$ three times daily and enalapril 5 $\mathrm{mg}$ three times daily. These lower doses had a beneficial effect on ventricular function. 
In the early intervention studies, SAVE used $50 \mathrm{mg}$ of captopril thrice daily, while in AIRE, ramipril was given as $5 \mathrm{mg}$ twice daily. Both of these trial doses are regarded as on the high side. In SAVE, $79 \%$ of the population achieved the target dose, although it was a highly selected population which was trialed. Likewise in AIRE, $77 \%$ achieved the target dose. Smaller trials with left ventricular function as the end point suggest that smaller doses will attenuate remodelling changes. ${ }^{26} 27$

There is a current notion that complete suppression of the renin-angiotensin system for the full 24 hours is the desired goal of treatment. This is based on the theoretical belief that complete suppression of the reninangiotensin axis is needed for the full potential of this therapy to be explored. Chobanien et $a l^{28}$ used a dose equivalent of $3000 \mathrm{mg}$ of captopril daily for an anti-atherosclerotic effect in the Watanabe rabbit. Captopril administration to Watanabe rabbits produced plasma captopril concentrations comparable to those induced in man by therapeutic captopril doses. Currently, there are two large studies, the NETWORK and the ATLAS, which will address the question of dosing. The NETWORK study will examine the effects of enalapril at $2.5 \mathrm{mg}, 5 \mathrm{mg}$, and $10 \mathrm{mg}$ twice daily for six months, looking at a combined end points of death, hospital admission for heart failure, and worsening heart failure. The ATLAS study will measure the effect of low and high doses of lisinopril $(2.5$ or $5 \mathrm{mg} v 32.5$ or $35 \mathrm{mg}$ ) on mortality. These are heart failure studies rather than acute myocardial infarction studies, but the results will be of relevance to the infarction situation.

\section{Mechanical remodelling or continuing cell death}

The initial paradigm on which the use of ACE inhibitors after acute myocardial infarction was based was that of ventricular mechanical remodelling. As discussed above, this hypothesis states that loss of myocytes leads to increased wall stress on the surviving myocardium. The increased wall stress leads to ventricular hypertrophy to normalise the wall stress, and to ventricular dilatation to preserve stroke output. The hypothesis also states that this is a generic response of the heart to increased wall stress, irrespective of its cause. An increased wall stress from any cause leads to progressive decline in myocardial function consequent to the dilatation/hypertrophy response. This was termed by Katz as the "cardiomyopathy of overload". 29 ACE inhibitors were thought to work by attenuating these remodelling changes by reducing preload and afterload.

Recently, it has become apparent that the story may be more complex. One study suggests that a combination of hydralazine and isosorbide dinitrate is much better at reducing left ventricular size than enalapril, but the impact of enalapril on mortality is much greater than the combination. ${ }^{30}$
Long term treatment with ACE inhibitors after acute infarction may reduce the incidence of recurrent infarcts and unstable angina. ${ }^{25} 31$ This is unlikely to be related to mechanical factors. This is also a reason for reduction in further ventricular damage and hence progression of heart failure. The role of coronary microvessels and the cytoskeleton in the genesis of progression of heart failure has been reviewed by LeJemtel. ${ }^{32}$ These developments suggest that left ventricular dilatation is the result of continuing cell death caused by coronary microvascular spasm, increasing myocardial fibrosis, and genetic reprogramming of cell death (apoptosis). These adverse changes are mediated by angiotensin II and catecholamines, which explains the beneficial effects of ACE inhibitors following myocardial infarction.

As Tan and $\mathrm{Hall}^{33}$ argue, post-infarction ventricular dilatation is a physiological adaptive mechanism to myocyte loss, not the cause. Putting an infarcted heart in a steel box will prevent it from dilating but will not make it perform better. In their words, "It is not the dilatation itself that needs to be dealt with, but the factors precipitating the adaptive dilatation".

\section{Conclusion}

It would appear that the ventricular remodelling hypothesis must be further modified and extended in the light of recent advances in our understanding of the anti-ischaemic and growth promoting roles of angiotensin II.

1 Pfeffer MA, Braunwald E. Ventricular remodeling after myocardial infarction. Experimental observations and clinical implications. Circulation 1990;81:1161-72.

2 Hutchins GM, Bulkley BH. Infarct expansion versus extension: two different complications of acute myocardial infarction. Am $\mathcal{F}$ Cardiol 1978;41:1127-32.

3 Leung WH, Lau CP. Effects of severity of the residual stenosis of the infarct-related coronary artery on left ventricular dilation and function after acute myocardial infarction. 7 Am Coll Cardiol 1992;20:307-13.

4 Fletcher PJ, Pfeffer JM, Pfeffer MA, Braunwald E. Left ventricular diastolic pressure-volume relations in rats with healed myocardial infarction. Effects on systolic function. Circ Res 1981;49:618-26.

5 Pfeffer JM Pfeffer MA, Fletcher PJ, Braunwald E. Pre JM, Pfer Progressive ventricular remodeling in the rat with Pyocardial infarction. Am f Physiol $91,29 . \mathrm{H} 1406-14$ feffer JM, Pfeffer MA, Braunwald E. Influence of chronic captopril therapy on the infarcted left ventricle of the rat

7 Pfeffer MA, Pfeffer JM, Steinberg C, Finn P. Survival after an experimental myocardial infarction: beneficial effects of long-term therapy with captopril. Circulation 1985;72. 406-12.

8 Pfeffer MA, Lamas GA, Vaughan DE, Parisi AF, Braunwald E. Effect of captopril on progressive ventricular dilatation after anterior myocardial infarction. $N$ Engl 7 Med 1988;319:80-6.

9 Sharpe N, Murphy J, Smith H, Hannan S. Treatment of patients with symptomless left ventricular dysfunction after myocardial infarction. Lancet 1988;i:255-9.

10 Pfeffer MA, Braunwald E, Moye LA, Basta L, Brown EJ, Cuddy TE, et al. The SAVE Investigators. Effect of captopril on mortality and morbidity in patients with left ventricular dysfunction after myocardial infarction. Results of the survival and ventricular enlargement trial. $N$ Engl f Med 1992;327:669-77.

11 The Acute Infarction Ramipril Efficacy (AIRE) Study Investigators. Effect of ramipril on mortality and morbidity of survivors of acute myocardial infarction with clinical evidence of heart failure. Lancet 1993;342:821-8.

12 The SOLVD Investigators. Effect of enalapril on survival in patients with reduced left ventricular ejection fractions and congestive heart failure. N Engl f Med 1991;325: 293-302.

13 The SOLVD Investigators. Effect of enalapril on mortality and the development of heart failure in asymptomatic patients with reduced left ventricular ejection fractions (published erratum appears in $N$ Engl 
14 Swedberg K, Held P, Kjekshus J, Rasmussen K, Ryden L, Wedel $H$. Effects of the early administration of enalapril on mortality in patients with acute myocardial infarction. Results of the Cooperative New Scandinavian Enalapril Survival Study II (CONSENSUS II). $N$ Engl $\mathcal{f} \mathrm{Med}$ 1992;327:678-84.

15 Schoemaker RG, Debets JJ, Struyker-Boudier HA, Smits IF. Delayed but not immediate captopril therapy improves cardiac function in conscious rats, following myocardial infarction. $f \mathrm{Mol}$ Cell Cardiol 1991;23: myocardial

16 ISIS-4 (Fourth International Study of Infarct Survival) Collaborative Group. ISIS-4: a randomised factorial trial assessing early oral captopril, oral mononitrate, and intravenous magnesium sulphate in 58,050 patients with suspected acute myocardial infarction. Lancet 1995;345

17 Gruppo Italiano per lo Studio della Sopravvivenza nell'infarto Miocardico. GISSI-3: effects of lisinopril and transdermal glyceryl trinitrate singly and together on 6week mortality and ventricular function after acute myocardial infarction. Lancet 1994;343:1115-22.

18 Oral captopril versus placebo among 13,634 patients with suspected acute myocardial infarction: interim report from the Chinese Cardiac Study (CCS-1). Lancet 1995 345:686-7.

19 Cleland JG, Poole-Wilson PA. ACE inhibitors for heart failure: a question of dose. Br Heart f 1994:72.S106-10.

20 van Gilst WH, de Graeff PA, Scholtens E, de Langen CD, Wessling $\mathrm{H}$. Potentiation of isosorbide dinitrate-induced coronary dilatation by captopril. $\mathcal{F}$ Cardiovasc Pharmacol 1987;9:254-5.

21 Foy SG, Crozier IG, Turner JG, Richards AM, Frampton CM, Nicholls $M G$, et al. Comparison of enalapril versus captopril on left ventricular function and survival three captopril on left ventricular function and survival three CAL" study). Am $\mathcal{\text { Cardiol }}$ 1994;73:1180-6.

22 Ambrosioni E, Borghi C, Magnani B. The Survival of Myocardial Infarction Long-Term Evaluation (SMILE) Study Investigators. The effect of the angiotensin-converting-enzyme inhibitor zofenopril on mortality and verting-enzyme inhibitor zofenopril on mortality and Med 1995;332:80-5.
23 Kober L, Torp-Pedersen C, Carlsen JE, Bagger H, Eliasen $\mathrm{P}$, Lyngborg $\mathrm{K}$, et al. Trandolapril Cardiac Evaluation (TRACE) Study Group. A clinical trial of the angiotensin-converting-enzyme inhibitor trandolapril in patients with left ventricular dysfunction after myocardial infarction. $N$ Engl f Med 1995;333:1670-6.

24 Ball SG, Hall AS. What to expect from ACE inhibitors Ball SG, Hall AS. What to expect from ACE inhibitor
after myocardial infarction. Br Heart $\mathcal{F} 1994 ; 72: S 70-4$.

25 Rutherford JD, Pfeffer MA, Moye LA, Davis BR, Flaker GC, Kowey PR, et al. SAVE Investigators. Effects of captopril on ischemic events after myocardial infarction. topril on ischemic events after myocardial infarction. Circulation 1994;90:1731-8.

26 Sharpe N, Smith H, Murphy J, Greaves S, Hart H, Gamble $\mathrm{G}$. Early prevention of left ventricular dysfunction after myocardial infarction with angiotensin-convertingenzyme inhibition (published erratum appears in Lancer 1991;337:1174). Lancet 1991;337:872-6.

27 Ray SG, Pye M, Oldroyd KG, Christie J, Connelly DT, Northridge $\mathrm{DB}$, et al. Early treatment with captopril afte acute myocardial infarction. Br Heart $¥ 1$ 1993;69:215-22.

28 Chobanian AV, Haudenschild CC, Nickerson C, Drago R. Antiatherogenic effect of captopril in the Watanabe heritable hyperlipidemic rabbit. Hypertension 1990;15: 327-31.

29 Katz AM. Cardiomyopathy of overload. A major determinant of prognosis in congestive heart failure. $N$ Engl $\mathcal{f}$ Med 1990;322:100-10.

30 Cohn JN, Johnson G, Ziesche S, Cobb F, Francis G, Tristani F, et al. A comparison of enalapril with hydralazine-isosorbide dinitrate in the treatment of chronic congestive heart failure. $N$ Engl F Med 1991;325: chronic con 10 .

31 Yusuf S, Pepine CJ, Garces C, Pouleur H, Salem D, Kostis $\mathrm{J}$, et al. Effect of enalapril on myocardial infarction and $\mathrm{J}$, et al. Effect of enalapril on myocardial infarction and
unstable angina in patients with low ejection fractions. unstable angina in patie

32 LeJemtel TH. Progressive left ventricular dysfunction: mechanical remodeling versus continuous cell loss. Heart Failure 1994;10:28-40

33 Tan LB, Hall AS. Cardiac remodelling. Br Heart $\mathcal{f} 1994$; 72:315-6. 